\title{
Los idilios del mundo petrificado: Stine de Theodor Fontane o el asedio de la inhumanidad
}

\section{The Idylls of the Petrified World: Theodor Fontane's Stine or the Siege of Inhumanity}

\author{
Ricardo Andrade \\ Universidad de Buenos Aires \\ andrader218@gmail.com \\ Orcid: https://orcid.org/0000-0002-6422-0809
}

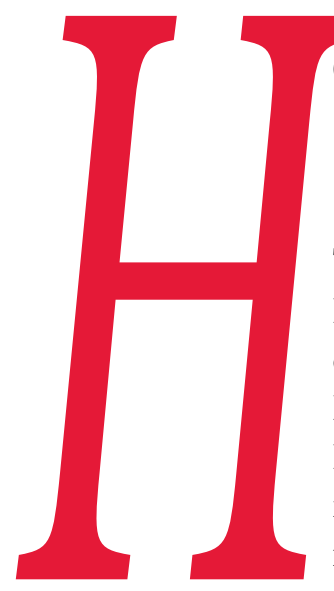

eil dir im Siegerkranz: contexto socio-polífico del autor y la novela

Detenerse en el contexto socio-político de los primeros años del Imperio Alemán (18711918) es fundamental para comprender los mecanismos sociales e ideológicos que expone Theodor Fontane (1819-1898). Ganada la batalla de Sedán en 1870 contra el Segundo Imperio Francés de Napoleón III, el Reino de Prusia logra consolidar su posición política en el territorio alemán bajo el liderazgo de Guillermo I y el canciller Otto von Bismarck. La Bismarckzeit será el período en donde Alemania no solo alcanza su unificación como Imperio, sino también el desarrollo económico a partir de las políticas destinadas a la plena industrialización. Los primeros años del Imperio son conocidos como el Gründerzeit (años fundacionales) que termina con el crack de 1873. En el contexto político-histórico europeo, se debe comprender que «The foundation of the German Empire signified a revolution "from above", facilitated by military conquest and agreed by princes. It appeared to present a definitive solution to the problem of political fragmentation which had bedevilled German-speaking Europe throughout the nineteenth century» (Lerman 2008: 20). El concepto de «revolución desde arriba» es acertado para explicar la formación de una nueva noción de comunidad, ya que el Imperio transformó las concepciones de poder y de relaciones sociales en el marco de una progresiva burocratización y militarización de la vida civil, al mismo tiempo que las políticas de bienestar social impulsadas por el canciller Bismarck generaban una fuerte popularidad entre los ciudadanos. Estas medidas sociales estaban destinadas a desarticular la influencia del incipiente Partido Socialdemócrata Alemán (SPD) y a promover la cohesión social de las clases trabajadoras para con el proyecto imperialista ${ }^{1}$. Estas directrices políticas formaban parte de un entramado mucho más complejo denominado Kulturkampf (lucha cultural). El Kulturkampf (1871-1879), al ser política de Estado, buscaba neutralizar a los componentes sociales, políticos y religiosos que trataban de desestabilizar o perturbar la hegemonía prusiana. Si bien la expresión se circunscribe a la lucha política y cultural contra el arraigado catolicismo de los Estados del sur 


\section{Resumen:}

El presente artículo busca reflexionar sobre los mecanismos sociales, políticos e ideológicos en el período de la fundación del imperio alemán (Gründerzeit) a través de una novela poco estudiada de la producción literaria de Theodor Fontane: Stine. A través de esta novela, el autor expone las contradicciones inherentes del incipiente capitalismo alemán y su unión con un elemento central de la política de su tiempo, el prusianismo. Nacido de los estratos sociales terratenientes y aristocráticos reaccionarios, la ideología prusiana es un elemento importante para entender el proyecto imperialista de Alemania y sus últimas consecuencias, manifestadas estas en el nacionalsocialismo. En este sentido, el artículo propone una lectura, a través de la literatura, de los orígenes de dicha tendencia política en la vida nacional del país germano. Por medio de este análisis, también se problematiza sobre la noción de realismo en el ámbito literario específicamente alemán.

Palabras clave: Theodor Fontane, Prusianismo, Literatura alemana, Realismo en Alemania, Stine

\section{Abstract:}

The present article seeks to reflect on the social, political and ideological mechanisms in the period of the German empire's foundation (Gründerzeit) through a little-studied novel of Theodor Fontane's literary production: Stine. Through this novel, the author exposes the inherent contradictions of the incipient German capitalism and its union with a central element of the politics of his time, Prussianism. Born out of the reactionary landed and aristocratic social strata, the Prussian ideology is an important element to understand Germany's imperialist project and its ultimate consequences, manifested in National Socialism. In this sense, the article proposes a reading, through literature, of the origins of this political tendency in the national life of the German country. Through this analysis, the notion of realism in the specifically German literary field is also problematized.

Keywords: Theodor Fontane, Prussianism, German literature, Realism in Germany, Stine

(más cercanos estos a Austria que a Prusia), la progresiva influencia del Partido Socialdemócrata Alemán en las clases trabajadoras replanteó la idea del enemigo interno. Las consecuencias de las victorias electorales del SPD logró un viraje en las relaciones entre el Zentrum (partido que representaba a los católicos) y el gobierno central. A partir de 1878, ambos frentes político-religiosos buscan desarticular el auge del socialismo y del comunismo entre las clases explotadas, cuyas condiciones de vida eran miserables. En este sentido, la «revolución desde arriba» construye su aparato estatal para enfrentar la posibilidad de una revolución de los obreros. A pesar de ello, cabe destacar la importancia de una figura dentro del socialismo alemán que, años antes, había consolidado el poder de Bismarck y su proyecto de una Alemania unificada: Ferdinand Lasalle (1825-1864) y su Asociación General de Trabajadores, predecesores del SPD.

El desarrollo y la eficiencia de la «revolución desde arriba» proviene de una clase social particular en el Imperio alemán: los Junker. Originarios de Prusia, los Junker tendrán un peso especial en el desarrollo económico, militar y político de Alemania hasta el final de la Segunda Guerra Mundial. Una síntesis acertada del desenvolvimiento histórico de esta clase se halla en la siguiente reflexión:

Die Erfolg der Junker als ländliche Elite beruhte vor dem 19. Jahrhundert auf einer Reihe von Faktoren, die hier in ihrer Bedeutung nur kurz angerissen werden können: der Kommerzialisierung der ostelbischen Getreidewirtschaft, die seit dem 15./16. Jahrhundert im Zuge der ökonomischen Ost-West-Differenzierung die Ausbildung eines adligen Unternehmertums begünstigt hat; der Kombination ökonomischer und politischer Herrschaft mit System der Gutherrschaft und Gutwirtschaft; der Art und Weise, in welcher der Adel durch den preußischen Absolutismus domestiziert wurde, und der Stellung, die er im gesellschaftlichen Gefüge des 18. Jahrhunderts einnahm (Schissler 1980: 91).

El primer elemento característico de los Junker era la arraigada relación que mantenían con la tierra. Esta condición de terratenientes les permitió enfrentarse, con cierto éxito, a la progresiva burocratización propia de los Estados modernos europeos. Este enfrentamiento contra el poder centralizado logró sedimentar las bases de su condición de clase, al mismo tiempo que les permitía mantener un margen importante de acciones para 
la consolidación de su ideología, cuya máxima expresión a finales del siglo XIX era la consigna de Blut und Boden. Esta consigna, que significa Sangre y suelo, remarcaba las tendencias racistas y económico-idealistas que los Junker desarrollaron para confrontar los procesos de Ilustración que se gestaban en Alemania desde el siglo XVIII, entre ellos el liberalismo burgués y el auge del marxismo. La absorción del poder prusiano central de esta clase desarrollará, como política de Estado, el irracionalismo militarista que se definirá a través de la noción de dominio (Herrschaft). Esta palabra, cuyo contenido semántico también designa lo señorial, habla de un control absoluto de la vida ciudadana. La palabra absoluto es de vital importancia, ya que posee una larga tradición en el pensamiento alemán, particularmente en el idealismo y en el romanticismo. La apropiación de esta idea, en el marco político, tiñó la burocracia prusiana con un militarismo idealista, creando de este modo una defensa de la Kultur a través de la irracionalidad y la violencia auspiciada por los Junker. La política estatal bismarckiana profundiza, de manera radical, la diferencia entre Zivilisation (herencia del pensamiento francés e inglés) y la Kultur. En este sentido, se puede decir que

La unificación alemana no se había logrado gracias a la política, sino a la cultura. Durante mucho tiempo, los alemanes estuvieron orgullosos de su condición de Kulturvolk, cuya autoestima no se veía afectada por la ausencia de un Estado unificado. Los franceses admiraban esta autosuficiencia, pero todo cambiaría a raíz de las conquistas napoleónicas y las guerras de liberación. Los alemanes, tan orgullosos de oficiales como Blücher, Gneisenau y Scharnhorst, se habían dado cuenta de que la cultura no había sido suficiente para derrotar a Napoleón. Como dice Hugh Trevor-Roper, «A partir de 1815, el Kulturvolk alemán tuvo que reconocer que solo podría competir en el mundo de la política moderna si contaba con la protección de un Estado poderoso: si el Kulturvolk se convertía en un Kulturstaat» (Lepenies 2008: 28).

Esta noción de Kulturstaat concreta, de manera acertada, la función del Estado alemán a partir de la unificación imperial. Esto se logra a través de la Kulturkampf iniciada por los Junker (se debe tener en cuenta que el propio Bismarck pertenecía a esta clase social), otorgándole más espacio en la construcción de una nueva comunidad orientada hacia una hipóstasis de lo cultural como fuerza espiritual y cohesiva. Esta exacerbación de la cultura tiene dos elementos como base. El primero, la progresiva distorsión de los valores del liberalismo burgués al plegarse estos a la conducción política del conservadurismo de los terratenientes bajo la premisa del anticlericalismo; el segundo está más relacionado con una apatía generalizada, por parte de la burguesía alemana, hacia la política. Esta apatía, acrecentada por los avances tecnológicos, le dará espacio al Kulturpessimismus, es decir, a una visión negativa de la existencia por el desarraigo y la fascinación de los avances tecnológicos propios de la industrialización y los cambios culturales que ello genera. Desde esta perspectiva, el Kulturstaat alemán se gesta a partir de elementos profundamente nacionalistas y reaccionarios, al mismo tiempo que explota la atomización, los prejuicios de clase y la rebeldía (en su mayoría expresada a través del arte) de los sujetos. Estas características son las que forman, a su vez, el Volk. A través del nacionalismo y los rituales político y míticos que crea y el tenue nihilismo de la incipiente burguesía, el Imperio alemán le da forma a su rebelión y diferenciación ante la Zivilisation franco-inglesa.

A la par de la fuerte influencia de los Junker, el desarrollo de la pequeño y la acaudalada burguesía es central para comprender las dinámicas sociales de las primeras décadas del Imperio alemán. Con el auge de la industrialización, las nociones de personalidad y libertad asociadas al liberalismo decimonónico se ven profundamente afectadas. Ambos conceptos son anudados en el problemático concepto de individualismo. Con respecto a esta representación conceptual en Alemania, cabe destacar que

Der neuzeitliche „Individualismus“ wurzelt in Pietismus, Aufklärung, Romantik und Neuhumanismus. Und Liberalismus, so wie er sich nach 1815 als „Denkstil“ einer außerständischen Intelligenz, vornehmlich von Beamten und Bildungsbürgern, entwickelt, richtet seine Entwürfe einer bürgerlichen Gesellschaftsordnung sehr selektiv an diesen heterogenen philosophischen Traditionen aus. Allein die Selbstbezeichnungen machen dies deutlich. So macht der Begriff „Individualismus" selbst erst im letzten Jahrhundertdrittel Karriere, und dort häufig als abwertenden Fremdbezeichnung. Von der Sache her reicht das semantische Feld - begriffsgeschichtlich kaum untersucht - vom aufklärerischen "Autonomie“ in den staatswissenschaftlichen Vormärzlexika, über das romantische „Individualität“, auch das neuhumanistische „Persönlichkeit“ bis zur parteipolitischen Programmbezeichung „Freisinn“ (Hübinger 1993: 61). 
El primer elemento a destacar son las raíces del individualismo. El pietismo, con su creación de un diálogo con Dios sin mediación alguna, desarrolla la posibilidad de un mundo interior abocado hacia las cualidades reflexivas de los sujetos y la soledad. De ahí que esta influencia sea central para comprender la posterior atomización del sujeto bajo el capitalismo industrial, además de sedimentar la irracionalidad como principio vital. Si el desarrollo del Volk nace de la necesidad de crear un Estado cultural y una comunidad, la influencia pietista en el individualismo alemán crea una contradicción con estos presupuestos, aunque, de forma paradójica, también fundamenta la apatía hacia una praxis política consecuente y revolucionaria. A su vez, el componente religioso en la formación de la noción de individualismo burgués lo anuda, de manera inevitable, a las posiciones ideológicas de los Junker. En este sentido, la sumisión hacia la voluntad de Dios se transforma, consecuentemente, en la obediencia absoluta prototípica del militarismo prusiano.

Se puede observar, a partir de esta reflexión, que el pietismo sedimenta las bases de la Ilustración alemana, al mismo tiempo que alimenta las exploraciones artísticas e intelectuales del romanticismo y le da forma, en el ámbito reflexivo y cultural, a la personalidad como concepto burgués. En el Romanticismo, esta noción llega a su última expresión en la hipóstasis del Yo. La absolutización del Yo, si bien permite una mayor comprensión de las experiencias humanas individuales, cierra el camino hacia una compresión de la realidad social mucho más certera. De ahí que el Romanticismo exprese, de manera mucho más problemática, la relación entre el Volk y la autonomía individual, ya que el movimiento busca anudar ambos elementos. En este sentido, el concepto burgués de personalidad termina por manifestar, también, la noción de nación y nacionalidad. Estos últimos conceptos son desarrollados, con mayor fuerza, a partir de las Befreiungskriege contra Napoleón Bonaparte, de manera que, a través de la guerra, el desarrollo de la personalidad y la nación adquieren connotaciones violentas ligadas al desenvolvimiento de las masas.

Si la autonomía es un elemento central dentro del individualismo, este se ve, de manera radical, afectado por la unificación alemana bajo Prusia. El prusianismo logra absorber estos valores para transformarlos en una inflexible noción de la sociedad, en donde la vida individual queda supeditada a la posición de clase. En este sentido, cabe destacar que

In many respects, the bourgeoisie's striving for honours, their self-discipline, their eagerness to serve in the reserve officer corps, their codes of honour, their insistence on social distinctions, and their frequently authoritarian managerial style were all indicative of their independence and support for the state on their own terms - not, that is, a sign of their subordination to another class. In this way the German bourgeoisie achieved a significant measure of internal cohesion (Hewitson 2008: 42).

La burguesía, como esta reflexión revela, mimetiza el comportamiento ideológico de los Junker. La cohesión de clase pasa por la profunda similitud que tienen con el señorío, de modo que el liberalismo burgués queda, bajo esta perspectiva, anulado. Esta abdicación de los valores liberales frente al incipiente aparato capitalista y burocrático de la Alemania imperial permite vislumbrar, por un lado, la carencia y el conformismo político de dicha clase; por otro, la falta de un proyecto político y social democrático y republicano. En este sentido, la burguesía alemana se pliega bajo la idea de la Kultur, a diferencia de sus pares franceses e ingleses que, si bien con grandes matices, tratan de mantener los principios políticos que fundamentan un Estado y una sociedad moderna constantemente contradictoria. Al mimetizar las actitudes de los Junker (e, inclusive, exacerbarlas como modo de afianzamiento social), la burguesía se transforma en un apéndice del fanatismo militarista y autoritario que caracteriza al Estado prusiano. Este mimetismo es mucho más complejo si se recupera el concepto de autonomía. Si la autonomía es un ejercicio de individualidad y de personalidad, estas se ven opacadas por el anhelo burgués de la distinción social. La personalidad, en este punto, esta mediada por la violencia intrínseca de la ideología de los Junker: la afirmación de ella pasa por la abolición de los deseos del sujeto o su transformación en modos represivos de representar y actuar en la realidad. La asfixia burguesa pasa a construirse, de este modo, en un cuerpo político que vitaliza, de forma opresiva, a la sociedad.

Es ilustrativo destacar, en este punto, las críticas que realiza el joven Karl Marx al prusianismo mucho antes de la unificación imperial alemana, específicamente en 1844. En esta demoledora crítica, menciona el pensador alemán que 
Hay que decir que Alemania revela tanta vocación clásica por la revolución social, como incapacidad para la revolución política. Pues así como la impotencia de la burguesía alemana es la impotencia política de Alemania, la capacidad del proletariado alemán aún prescindiendo de la teoría alemana- es la capacidad social de Alemania. La despreocupación entre el desarrollo filosófico y el desarrollo político no es, en Alemania, ninguna anomalía. Representa una desproporción necesaria. Solamente en el socialismo puede un pueblo filosófico encontrar su práctica adecuada y, por tanto, solamente en el proletariado puede encontrar el elemento activo de su liberación (Marx 1982: 517. Las cursivas son del autor).

En esta reflexión, Marx sintetiza el problema del desarrollo de la burguesía alemana: su incapacidad de hacer una polis, es decir, una ciudadanía que encuentre en la autonomía su mayor representación. Esta carencia de una ciudadanía (con los motivos cosmopolitas y universales que conlleva) es el pilar fundamental del Estado prusiano y de la ideología de los Junker compartida por la burguesía. Si bien la educación prusiana se detenía en una formación profundamente cultural de los sujetos, estos se encontraban subyugados al aparato estatal absolutista, de manera que, en el desarrollo teórico burgués, la autonomía tiene un peso central, mas en la praxis social se ve anulada por omnipotencia autoritaria característica del prusianismo. En este sentido, la existencia de un Kulturvolk implicaba la erradicación de cualquier tentativa política democrática, haciendo de la cultura un elemento más de coacción social. El Volk, desde esta perspectiva, se construye a partir de la mitificación y no de la emancipación. El límite de la Ilustración alemana se halla en este punto. Frente a la asfixia burguesa y su impotencia política, Marx encuentra en el proletariado la capacidad de pensar lo alemán desde una perspectiva que anuda no solo la revolución social, sino también la política y la filosófica. Si los límites de la burguesía impiden la consolidación de lo político, este último se desarrolla plenamente a través del movimiento de los trabajadores. Es ilustrativo el término pueblo filosófico que Marx acuña. Por la filosofía, es decir, por el acto de pensar radicalmente lo existente, se puede abrir el camino hacia las fuerzas intelectuales y políticas que permitan crearle, a los ciudadanos, una autonomía que vaya más allá del Estado. De ahí que la crítica que realiza Marx vaya mucho más allá del Estado prusiano y se sitúe en un ataque hacia el Estado moderno capitalista, absolutista y burgués. En este sentido, Marx señala que

El Estado no puede superar la contradicción entre la disposición y buena voluntad de la administración, de una parte, y de otra sus medios y su capacidad de destruirse a sí mismo, ya que descansa sobre esta misma contradicción. Descansa en la contradicción entre la vida pública y la vida privada, en la contradicción entre los intereses generales y los intereses particulares. De ahí que la administración deba limitarse a una actividad formal y negativa, pues su acción termina allí donde comienza la vida civil y su labor. Más aún, frente a las consecuencias que se derivan del carácter antisocial de esta vida civil, de esta propiedad privada, de este comercio y esta industria, de este mutuo saqueo de los diversos círculos civiles, es la impotencia la ley natural de la administración. En efecto, este desgarramiento, esta vileza, esta esclavitud de la sociedad civil, constituye el fundamento natural en que se basa el Estado moderno, lo mismo que la sociedad civil de la esclavitud constituía el fundamento sobre el que descansaba el Estado antiguo. La existencia del Estado y la existencia de la esclavitud son inseparables (Marx 1982: 513. Las cursivas son del autor).

Esta esclavitud de la vida civil se desarrollará con mayor profundidad bajo la ideología prusiana. El prusianismo supedita la vida pública al entramado privado, de forma que el autoritarismo de las estructuras estatales se pliegan a la vida interior de los individuos. Marx sitúa estas imbricaciones entre ambas manifestaciones en forma de intereses. No es fortuito el uso del concepto económico: el desarrollo del capitalismo alemán, que se gesta entre la industria y los terratenientes, media de forma negativa y constituye la destrucción de toda organización civil que se sustente en la libertad. En este sentido, la impotencia (término que Marx usa insistentemente en este escrito) se transforma en la única opción aparente para pensar la vida civil en la modernidad. Esta concepción se acrecienta con el fracaso de las revoluciones de 1848 y el progresivo desmoronamiento político de la burguesía en favor del proyecto imperialista de Bismarck y los Junker. La forma de recuperar la vida civil en la modernidad, para Marx, está en el proletariado filosófica y políticamente preparado para construir un proyecto alternativo. Situar este proyecto en el marco del Imperio Alemán demuestra no solo el auge del SPD, sino también la unificación de todas las fuerzas reaccionarias y burguesas bajo la tutela de Bismarck para destruir dicha alternativa.

Como se ha observado, el contexto socio-político de Fontane es fundamental para comprender el desarrollo 
de su narrativa y, especialmente, de Stine. Los problemas planteados en este apartado son puestos en escena en la novela de forma mucho más evidente y palpable.

\section{Stine: la hipóstasis del mundo petrificado. Análisis de la novela}

La publicación de Stine data entre 1889 y 1890, encuadrándose en el realismo literario. Cabe señalar que, en Alemania, el desarrollo del realismo se da con unos matices bastante evidentes en relación con el movimiento europeo en general. En el momento de la escritura de Stine, el auge del idealrealismo es central y tiene como influencia clave la filosofía hegeliana. El idealrealismo, basado en la abstracción y el desprecio hacia la cotidianidad y la fealdad, buscaba crear ideales de tono moral y estético. En este sentido, se puede decir que

Fealdad y cotidianidad: así rezan los conceptos globales para lo socialmente chocante, para la banalidad rechazada, que los realistas desearían sumergir en el suave brillo de la reconciliación y la transfiguración. El realismo está siempre atravesado de manera idealista, está dividido y está provista de una máscara mendaz de normatividad. No ha pasado nada malo. Aún en la muerte resplandece el brillo de la bella apariencia; siempre son bellos cadáveres, en oposición al horrible cuerpo ahogado que Zola describió ásperamente, de manera naturalista, en su temprana Thérese Raquin (1867) (Jung 2011: 21).

Esta reflexión introduce tres elementos problemáticos: reconciliación, transfiguración y normatividad. Como se verá detenidamente, en Stine los tres momentos harán aparición de forma irresoluble. Lo que se debe destacar en este punto es el problema subyacente a la hora de elaborar una crítica social que descansa en la concepción de la novela alemana del período de la unificación imperial. La impotencia (para utilizar el término ya visto de Marx) de la burguesía alemana se trasluce en esta incapacidad para indagar, de modo más concreto, la miseria social y la estrechez propia del orgullo de clase. La novela ideal-realista busca suprimir estos puntos en favor de la armonía de una sociedad en pleno desarrollo de la orfandad espiritual y material propia de la industrialización en masa. Lo ideal, en este sentido, esconde los horrores de la explotación y de la banalidad social.

En términos formales, la novela está estructurada en capítulos, lo cual evidencia el intento, por parte de Fontane, de mostrar en un nivel microscópico las estructuras sociales y psíquicas de los personajes. Esta necesidad de describir tipos sociales viene aparejada con el intento de hacer una escritura que se asemeje a las exploraciones pictóricas. La introducción que realiza Fontane de las hermanas Pittelkow (Pauline y Ernestine) en el capítulo primero se da en el marco de un comentario negativo por parte de una vecina, Lierschen. Frente a la descripción sensual que realiza el narrador de la viuda Pauline (limpiando una ventana con la falda hasta las rodillas), Lierschen evoca la construcción puritanista de la mujer. Llama la atención la preponderancia de un personaje secundario en la caracterización de un personaje principal: a través de lo periférico, Fontane construye la negatividad de lo social y lo expone en forma de prejuicio. En el mismo capítulo, la llegada de una carta es el detonante de toda la trama de la novela. En esa carta se anuncia la visita del barón Papageno, el conde Sarastro y el joven conde Waldemar, sobrino del segundo. La reacción de Pauline es de fastidio y enojo, evidenciando las tensiones de clase existentes entre los dos estratos sociales. Esta tensión se materializa en el propio espacio donde se desarrolla parte de la novela: la reconocida Invalidenstraße. Una clave de lectura se revela en este punto, ya que muestra la condición de inválidos sociales de la pequeñoburguesía alemana. Esta invalidez se hace palpable ante la necesidad material que tiene Pauline de soportar las visitas de los aristócratas, de manera que su existencia social tiene sentido en el marco de una coacción por su condición de mujer viuda y por el interés de mantener una vida relativamente digna para sí y sus dos hijos. La llegada de los aristócratas llama la atención por dos situaciones que el narrador presenta:

»Hat Borchardt geschickt?«

»Versteht sich, hat er..."

»Nun, dann bitt ich also... « Der ungewöhnliche Bestimmtheitston, in dem das alles von seiten Sarastros gesagt wurde, verschnupfte die Pittelkow nicht wenig, sie hielt es aber für angemessen, ihren Ärger darüber auf andere Zeit zu vertagen, und ging mit Stine hinaus, um den schon vorher gedeckten Tisch aus dem Hinterzimmer in das Vorderzimmer zu tragen. Inzwischen war der alte Graf, der sehr feine Nerven hatte, durch die Feuerlilien 
und ihren Geruch heftig inkommodiert worden; er nahm sie darum ohne weiteres aus dem Bouquet, öffnete das Fenster und warf sie hinaus.

»Ein mir unerträglicher Geruch; halb Kirchhof, halb Pfarrgarten. Und von beiden halt ich nicht viel.« (Fontane 1973: 191).

Tanto el tono firme como el desechar las flores forman parte de la conducta prusiana profundamente militarista que atraviesa al viejo conde. El desagrado de Pittelkow radica no solo en la incomodidad de su presencia, sino también en sus formas sociales autoritarias. A través de su irritación se hace visible la reacción de las clases menos pudientes frente al orden aristocrático existente. Es ilustrativo, al mismo tiempo, la impresión que le causan al viejo conde Haldern las flores. Mitad cementerio y mitad jardín de parroquia, ambas imágenes remiten a la muerte y la inocencia. Estas dos apreciaciones de la existencia habitan en el mobiliario pequeñoburgués y popular, de forma que ambos marcan la situación vital de las clases bajas alemanas del siglo XIX. El rechazo de Sarastro no solo se da en el marco de su visible vejez, sino también porque reconoce en las flores los elementos característicos del mundo popular que apuntan a desestabilizar su formación de Junker. A su vez, el «olor a parroquia» que el conde desprecia muestra un signo claro de la nobleza prusiana: su pretendido (y, en muchas ocasiones, impostado) liberalismo. De este modo, Fontane logra visibilizar, a través de símbolos que construyen la cotidianidad, la animadversión entre los sujetos por su condición social y su ideología. En las escenas de la vida cotidiana se desarrollan las banalidades políticas y morales que sustentan el Bismarckzeit. En este sentido, se debe añadir que

Theodor Fontane is the subtlest interpreter of the rapprochement between aristocracy and the middle-classes in the New Empire. Although he came from the middle-classes, he had an intimate knowledge of the nobility and was therefore able to describe the sociological structure of the Berlin upper strata, with a realism tempered with profound human understanding. His development shows in a unique way the peculiar attitude of a conservative writer oscillating between nobility and bourgeoisie (Bramsted 1964: 256).

Estos acercamientos que Fontane realiza a través de sus novelas berlinesas (en donde Stine tiene un lugar central) colocan el foco en el problema del reconocimiento. La visita de los Junker a las mujeres atestigua el anhelo, por parte de los primeros, de adecuarse a un tiempo histórico en donde la libertad tiene una impronta importante en la formación social, aunque su misma clase social la destruya a través del prusianismo. Al mismo tiempo que desean no pertenecer a ese estrato, son parte de él en la medida en que sus costumbres y sus prejuicios terminan por imponerse a la racionalidad o la democratización de la vida civil.

Teniendo en consideración esto, llama la atención una reveladora caracterización de las hermanas que realiza el narrador. Este menciona que «La viuda morocha era la imagen de la belleza sureña, mientras que la hermana menor podía considerarse del tipo de las rubias germánicas, si bien algo enfermiza» (Fontane 1973: 19). Bajo esta definición, cobra sentido el nombre de la novela. Lo que va revelando la trama de la obra es la enfermedad que corroe la vida individual suprimida por las exigencias y la estandarización moral. Esta descripción enfermiza no solo le atañe a Stine, sino también al hombre que se enamora de ella: el joven Waldemar. Este personaje también es descrito de forma negativa (débil, pálido), creando así una dualidad de personajes que buscan librarse, fútilmente, de las convenciones sociales. Esta corrosión de la vida individual por la enfermedad del prejuicio y su herencia cae sobre la juventud, cuya caracterización más visible es el anhelo del amor y la libertad. Lo generacional, entonces, juega un papel fundamental dentro de la novela, ya que evidencia, por una parte, el profundo conformismo de las viejas generaciones (Sarastro y, como se verá, también la propia Pauline) para con el status quo y, por otro lado, la incapacidad de una armonía entre las aspiraciones particulares y un sistema político-económico represivo. En este sentido, Stine puede ser catalogada como una novela de la vida dañada. Esta vida mutilada por múltiples factores (condición de clase y género, alienación, banalización de las ilusiones que forman lo humano) expresan, al mismo tiempo, el desarrollo tardío del capitalismo en Alemania. El empobrecimiento conlleva, en este sentido, a un estadio de sumisión que se naturaliza, puesto que termina siendo el único modo de mantenerse materialmente. Fontane da cuenta de la naturalización progresiva de la barbarie y la displicencia de los estratos sociales 
para con este modus vivendi socialmente aceptado y validado. Como señala acertadamente György Lukács:

Fontane es el primer escritor alemán que comprende que el sistema social y moral de la clase alta prusiana tiene el carácter de un automatismo inerte unas veces y destructor otras, y que en él no hay una fuerza intrínseca capaz de orientar el alma de los hombres. En efecto, las mejores narraciones de Fontane son las que se refieren al destino individual; en esa temática, las reivindicaciones más simples y elementales de la vida humana chocan con las barreras levantadas por los automatismos de la clase dirigente. El escéptico Fontane advierte claramente que es inevitable que esos choques acarreen la destrucción exterior e interior -o por lo menos esta última- de los hombres. Están obligados a someterse a estos imperativos sociales, pero para ello carecen ya del más mínimo poder de convicción moral. En la obra de Fontane el carácter fatídico e inhumano del prusianismo se expresa con sencillez y veracidad, sin indignación patética o satírica mediante un relato de profundo sentido psicológico y moral (Lukács 1971: 127).

$\mathrm{Al}$ aceptar el prusianismo como ideología total, este automatismo no solo pertenece ya a las clases altas, sino también son mimetizadas por la clase popular y pequeñoburguesa. La inhumanidad se instala como componente central entre las relaciones interpersonales, creando de este modo una sociedad propensa a la destrucción de la interioridad de los sujetos con consecuencias imprevisibles en la exterioridad. A pesar de esa mimesis generalizada, en la individualidad quedan rastros de una rebeldía contra el status quo. Esto se manifiesta en algunas partes de la novela. En el capítulo octavo, se presencia la eclosión del amor de Waldemar hacia Stine. En el encuentro entre los jóvenes enfermizos, surge un diálogo ilustrativo que habla, especialmente, del automatismo y la mimesis de la barbarie. Hablando de Pauline y las carencias materiales que la rodean, Stine menciona que

»Ja, das ist schwer zu sagen, aber es ist so und kann auch kaum anders sein. Denn die, die Not leiden, wollen vor allem aus ihrer Not und ihrem Elend heraus und sinnen und simulieren bloß, wie das zu machen sei. Brav sein und sich rechtschaffen halten, das ist alles sehr gut und schön, aber doch eigentlich nur was Feines für die Vornehmen und Reichen, und wer arm ist und das Feine mitmachen will, über den ziehen sie bloß her - und die gestern noch die Strengsten waren, am meisten - und reden und spotten, daß man was Apartes sein wolle. >Die denkt wohl, sie sei es.< Ach, wie oft hab ich das hören müssen."

»Welche Verworrenheit der Begriffe.«(Fontane 1973: 210).

La base de la reflexión de Stine se sustenta en el verbo simulieren. La alienación, al despersonalizar a los excluidos, los lleva a fomentar la ilusión de una vida mejor que culmina con el conformismo o el autodesprecio. En esas pulsiones destructivas se construye la individualidad de la pequeñoburguesía, dando nacimiento así a la naturalización de la alienación en el capitalismo. La hipóstasis de dicho esencialismo abstracto conlleva a pensar el reconocimiento en términos negativos, es decir, a través de la lucha a muerte, tanto metafórica como físicamente hablando. Al mismo tiempo, Stine desmorona, desde su perspectiva de mujer y de clase popular, la premisa extendida de la pobreza como virtud. La indignidad de la pobreza termina de ser sellada por las burlas de la alta burguesía y por los Junker. En este sentido, los personajes atados a su miseria material solo pueden ser entes sociales en el marco de su propia destrucción y rechazo. El automatismo que permite sostener dicha construcción social negativa se manifiesta en la respuesta del propio amado Waldemar. Fontane, de manera demoledora, evidencia que el amor no puede desarticular el profundo arraigo ideológico del prusianismo en el joven, aunque este aspire a una libertad que contrarreste la inhumanidad y le permita ver al otro de forma más humana. Por ello, su amor está mediado por la tensión entre la emancipación y la normatividad. Lo normativo, incólume ante las pasiones, se ve solo afectado de manera superficial, creando de este modo sujetos propensos a su propia abolición. El realismo de Fontane expone dicha normatividad en forma de prejuicios y falsas premisas político-sociales por parte de sus personajes. El aparato político-social que sustenta la normatividad prusiana se ve expuesto, de forma dolorosa, en una conversación que sostienen en el capítulo décimo Stine y Pauline sobre Waldemar. En dicho diálogo, Stine menciona que

»Und ich denke mir, ich kenn ihn auch und weiß, woran es liegt. Sieh, es liegt daran, er hat so wenig Menschen gesehen und noch weniger kennengelernt. In seiner Eltern Hause gab es nicht viel davon - sie sind alle stolz und hart, und seine Mutter ist seine Stiefmutter -, und dann hat er Kameraden und Vorgesetzte gehabt und hat 
gehört, wie seine Kameraden und seine Vorgesetzten sprechen; aber wie Menschen sprechen, das hat er nicht gehört, das weiß er nicht recht. Ich denke mir das nicht aus, ich hab es von ihm, es sind seine eigenen Worte. Ja, Pauline, daran liegt es. Das ist der Grund, daß ich armes Ding ihm gefalle; nichts weiter.« (Fontane 1973: 219. Las cursivas son del autor).

El comentario de Stine revela los mecanismos por los cuales la deshumanización comienza a volverse ideología estatal y social. Tanto el aislamiento (la atomización) como la carencia de un discurso ligado a los afectos forman el temple de los Junker. Ambos elementos, que son medios para socializar y formar campos de consciencia y afectividad, son negados por la normatividad prusiana. Waldemar desconoce lo humano y encuentra en las clases populares la pervivencia de un mundo otro, es decir, de un mundo que, bajo sus ojos, es mejor. En este punto se manifiesta la transfiguración de la vida individual, aunque con una impronta negativa. Lo negativo radica en que dicha transformación está mediada por la infelicidad característica de la posición de clase. Hacerse humano implica, bajo esta perspectiva, abandonar la herencia de un pensamiento anclado en la asfixia y la irracionalidad. A través del enamoramiento, Waldemar construye una racionalidad basada en la esperanza que contrarresta contra la manera de concebir la vida alemana a partir de la unificación imperial. Al mismo tiempo, no se puede perder de vista que la vida sencilla que posee Stine cae en la hipóstasis y es exaltada, para el público lector burgués de Fontane, como un medio de escape y de verdadera originalidad y naturalidad, cuando la realidad social concreta evidencia los tormentos de la pobreza en la industrialización masiva. En este sentido Fontane responde a las exigencias de la naciente cultura lectora masificada.

Llama la atención el peso que tienen, dentro de la novela, las mujeres. A través de la subjetividad femenina, como se ha visto en las intervenciones de Stine ya citadas, se hace patente un elemento clave: la subjetividad escéptica. Este escepticismo, que termina por transformarse en pesimismo, viene aparejado con la certeza de que la miseria material, bajo el sistema capitalista y paternalista, es natural a la condición humana. Dichas subjetividades se manifiestan a través de la dialogicidad. En este sentido, sobre lo femenino en Fontane, se puede aducir que

Indem Fontane deutlich macht, dass jeder moralische Objektivismus auch Lüge, auch Beschränktheit heisst, lässt sich das Resultat der verschiedenen Figurenperspektiven, die in den dialogisch strukturierten Romanen aufeinandertreffen, als Konfiguration lesen, die ein Bild und damit eine Anschauung, nicht aber eine These oder den fertigen Begriff einer Sache vermitteln. Die Darstellung der Realität als Konfiguration beinhaltet somit schon eine erste Revision der verschiedenen vorgeführten Imagines weiblicher Identität, indem sie nämlich als Projektionen einzelner Repräsentanten des gesellschaftlichen Perspektivsystems transparent werden. In diesem Sinne sind Fontanes Protagonistinnen dann oft genug ,anders" als die an sie herangetragenen Verhaltens - und Rollenanweisungen (Hanraths 1989: 164).

La subjetividad femenina desmonta la construcción negativa de la objetividad opresiva, de forma que la vida social se manifiesta a través de las apreciaciones ligadas a la insatisfacción, el automatismo y la rebeldía sin horizonte desde una perspectiva de género. La vida, en este sentido, pierde su elemento de praxis transformadora para devenir en una constante reflexión atomizada sobre la discrepancia entre los deseos individuales y las barreras ideológicas objetivadas que sepultan cualquier pretensión de un mundo mejor. Por ello que, tanto Pittelkow como Stine, aparecen como «diferentes», aunque la diferencia esté mediada por el sufrimiento. Lo diferente aparece para vislumbrar la vida dañada. El término anders designa no solo lo diferente, sino también lo otro. Si bien la diferencia y la otredad comparten un campo semántico, este último profundiza más en la noción de identidad. Bajo esta perspectiva, la identidad se construye a partir de la negatividad, anulándola de este modo y desplazando la posibilidad de la emancipación, vía concreta para desarticular el automatismo prusiano.

Un ejemplo manifiesto de las contradicciones políticas propias de los Junker y del prusianismo se hace patente en el capítulo decimosegundo, en donde Waldemar conversa con el conde Sarastro sobre su intención de formar una vida con Stine. Después de reunirse con el barón Papageno en busca de un consejo y un apoyo moral e ideológico en su tentativa, el joven decide enfrentar a la tradición encarnada en su tío. La conversación entre ambos es sugerente en cuanto muestra la falsa consciencia que atraviesa a las clases dirigentes alemanas en la época de la unificación imperial. Cuando Waldemar, de manera decidida, le expone a su tío sus pretensiones amorosas, la respuesta de Sarastro es: 
»Was heißt das? Was hast du vor? Waldemar, ich bitte dich, du wirst uns doch nicht eine dieser modernen Selbstmordskomödien aufführen und dich mit deiner Stine nach erfolgter Kopulation, das Wort bleibt mir in der Kehle stecken, auf eine Bahnschiene werfen oder im Hans-und-Grete-Stil in einen Dorftümpel stürzen wollen? Ich bitte dich, Waldemar, verschon uns wenigstens mit einem Debüt im Polizeibericht."

»Es ist nicht das. Ich habe nur einfach vor, mit der Alten Welt Schicht zu machen und drüben ein anderes Leben anzufangen.«

»Und als Hinterwäldler deine Tage zu beschließen. Umgang mit Chingachgook, alias le gros serpent, und Vermählung deiner ältesten Tochter Komtesse Haldern mit irgendeinem Unkas oder einem Großgroßneffen von Lederstrumpf. Was meinst du dazu? Und wenn nicht Hinterwäldler, so doch Cowboy, und wenn nicht Cowboy, so vielleicht Kellner auf einem Mississippidampfer. Ich gratuliere. Waldemar, ich begreife dich nicht. Ist denn keine Spur von Haldernschem Blut in dir? Ist es denn so leicht, aus einer Welt bestimmter und berechtigter Anschauungen zu scheiden und bei Adam und Eva wieder anzufangen? (Fontane 1973: 237-238).

En este ilustrativo diálogo, se entremezclan las posiciones reaccionarias, la visión imperialista y los clichés propios de lo europeo (específicamente, en este caso, desde la posición aristocrática alemana) sobre lo americano. El tono irónico y brutal de Sarastro contrarresta con la necesidad de la nueva generación de emanciparse de la deformación espiritual del prusianismo. La ironía funciona como un mecanismo para ridiculizar las ilusiones que alimentan la esperanza de un nuevo horizonte. Bajo esta perspectiva, el realismo de Fontane está íntimamente ligado a la ridiculización de los impulsos románticos que perviven en el pensamiento alemán del Gründerzeit. Es interesante resaltar que dicho espíritu romántico viene acompañado con una visión idealista de América, en donde la tierra desconocida se transforma en un paraíso para escapar a la asfixia de un mundo profundamente destructivo y carente de emociones. La ironía de Sarastro, a pesar de su profundo contenido reaccionario, desarticula dicho idealismo para situarlo en la realidad, es decir, lo demuele desde sus cimientos. De ahí que la «verdad» desesperanzadora se objetive y se transforme en una esencia innata en la sociedad capitalista y jerarquizada alemana. Si Waldemar hace una hipóstasis distorsionada de América al configurarla como un paraíso en el cual puede aspirar a despojarse de toda la historia de su clase social, Sarastro evidencia la futilidad de dicho proyecto a través del cliché, el racismo y el clasismo. A través de los componentes destructivos de la civilización (auspiciados por la incipiente economía burguesa de tintes proteccionistas y de «libre mercado», la literatura trivial estereotipada y el desprecio hacia la otredad propios en la consolidación de una visión imperialista), se hace patente la desilusión y el sinsentido de vivir propio de la Kulturpessimismus.El impulso romántico de Waldemar es una resistencia ante esta visión y normatividad existente, evidenciada además por el miedo de Sarastro ante el suicidio y el posterior castigo moral por ello. Frente a dicho impulso, las preguntas finales que esboza el viejo conde Haldern son esclarecedoras. Por una parte, el llamamiento a recordar sus orígenes a través de la sangre pone en relieve la construcción del mito del Blut und Boden; por otra parte, la última pregunta es un cuestionamiento al pensamiento y a la acción que pretenda remover no solo la tradición, sino también la ya instaurada racionalidad negativa mediada por la ideología. Conceptos justos y determinados (tradición, obediencia, fidelidad a la sangre) son, para la historia alemana a partir del siglo XIX, las directrices fundacionales del imperialismo, cuyo corolario final será el nacionalsocialismo en el siglo XX. El intento de Waldemar por desprenderse de dichas estructuras políticas y económicas alienantes se ve impedido por su tío y por la propia Stine, ya que esta rechaza la propuesta de matrimonio del joven. En este sentido, cabe destacar que

An outsider by virtue of his personal and military experiences, only Waldemar has formulated for himself an ideology of independence, albeit an independence which borders on alienation rather than genuine freedom from the prescribed societal norms. As a result, the perspectives he conjures up are illusions and unconvincing idylls. Unlike Waldemar, Stine is firmly rooted in her sphere, She experiences individuality and identity not by virtue seeing herself as a disjointed entity but through participation in her social group which gives her, in Hegelian terms, a determinate Stand, and thereby a place "in wirklicher Allgemeinheit". She derives her happiness and satisfaction from the honest work of her own hands, and paints rather pleasant picture of the bourgeois economy of which she is a part as a worker in a wool and embroidery house (Krause and Hicks 1995: 235-236).

Este contraste entre el anhelo de libertad de Waldemar y la fijación de Stine en su propia clase social se transforma en uno de los ejes centrales de la tragedia de la novela. Tragedia ya que, acorralado ante la normatividad existente, 
el joven decide quitarse la vida. Se observa de este modo que la independencia, en el marco del prusianismo, se da a través de la exaltación de la muerte y su concreción. La libertad se logra despojando, entonces, a los sujetos de su propia existencia. Stine evade esta cultura de la muerte y su exaltación a través de su conformismo de clase. Enraizada en la vida popular, la joven consigue mantenerse con vida a través de la alienación, es decir, por la deformación de su persona por la abstracción económica. De ahí que se pueda hablar de esferas sociales en la novela. La noción de esfera implica lo cerrado, en donde violentar dicho espacio significa morir por ser reconocido como persona autónoma (Waldemar). La sentencia de muerte de Waldemar es dictada por la totalidad del sistema socio-económico. Esto se evidencia con bastante fuerza en el capítulo décimo tercero, en donde el viejo conde se reúne con Pauline para terminar con el romance sin frutos de los jóvenes. Todo el capítulo es una conversación entre ambos. En un punto de la misma, el viejo conde menciona que

» $J$ a. Sie hat da mit meinem Neffen angebändelt. Und nun ist er verrückt geworden und will sie heiraten. Und wer ist schuld daran? $D u$, Pauline. Du hast mir dies eingebrockt. Du, nur du. Stine macht nicht drei Schritte, geht nicht von hier bis ans Fenster, ohne dich zu fragen; sie hat nie was andres getan, als was du gewollt oder gutgeheißen hast, und auf dich fällt dieser Skandal. Ich frage dich, ob ich Anspruch auf solche Behandlung habe? Nun, wir wollen sehen, was wird. Wolle $d u$, was du willst, ich will, was ich will. Die Welt ist verrückt genug geworden, aber so weit sind wir noch nicht, daß die Häuser Haldern und Pittelkow Arm in Arm ihr Jahrhundert in die Schranken fordern. Nein, Pauline. Solchen Unsinn verbitt ich mir, und was ich von dir fordre, ist das, daß du dieser Kinderei ein Ende machst.«

"Kann ich nicht."

»Weil du nicht willst.«

»Oh, ich will schon. Ich habe schon gewollt, gleich als ich die Geschichte kommen sah. Es ist ein Unglück für meine Stine.«

»Was?"

»Es is ein Unglück für meine Stine. Ja, Graf. Oder denken Sie, daß ich so dumm bin, so was für ,n Glück zu halten? Ach, du meine Güte, da sind der Herr Graf mal wieder aus Irrland (Fontane 1973: 244-245. Las cursivas son del autor).

Es llamativa la respuesta de la viuda Pittelkow ante las palabras del conde. Que la desgracia sea la manifestación más coherente de dicho intento por humanizar las relaciones sociales evoca los anclajes deshumanizantes en el que descansa el sistema capitalista promovido por los Junker. Desclasarse implica, bajo esta perspectiva, transgredir la naturalidad artificial creada por la economía y la sociedad burguesa-aristocrática, cuyo corolario es la muerte y la desesperanza y no la emancipación que conduce hacia una vida basada en la racionalidad. Luchar contra la ontologización nacida por las estructuras sociales es, en palabras del conde, desafiar a la historia. Tanto él como Pauline reconocen en ese desafío un error fatal y anti-natural, de forma que ambos pactan luchar contra las pretensiones de Waldemar y Stine. A la luz de esto, la rebeldía de Waldemar adquiere un elemento mucho más arriesgado: tratar de hacerse con una independencia implica rebelarse contra la concreción negativa de la historia. Al estar absorbido por la negatividad de la época, el desarrollo de la dialéctica de la emancipación del joven conde culmina con la muerte como contradicción y realización de su proyecto. Por la muerte, entonces, se manifiesta la reconciliación individual con la normatividad existente. Con respecto a esto, se puede aducir que

Fontane también describe cómo los diferentes tipos del Junker prusiano se modernizan, cómo se convierten en hombres de la sociedad burguesa actual. Pero todo lo que se apropiaron en cuanto a sentimiento y vivencia, en cuanto a cultura, da contra su "actitud" prusiana, que funciona de manera mecánico-fatalista. Por más que, privadamente, en sus sentimientos, sean también seres humanos cálidos e, incluso, internamente decentes, refinados, en sus acciones, persiste la inhumanidad de la moral prusiana y domina absolutamente, sin que los hombres estén en condiciones de tender un puente entre sus sentimientos y sus actos, prescriptos por la "actitud". Así resurge detrás de la fachada espléndida, a menudo, decente, siempre marcial, un mundo interno de plena inestabilidad, de desesperación resignada, de cinismo sentimental o fríamente arribista. Los valores vitales se echan a perder, los lazos de amor sentidos de manera auténtica se rompen, los hombres se matan en duelos, se pasa por encima de existencias, sin que haya una verdadera convicción ni sobre lo bueno, ni sobre lo malo (Lukács: 2019: 165). 
Este fatalismo que la novela recalca a partir de un valor vital como el amor se constituye como objetividad social en la Alemania prusianizada. Lo que busca Waldemar es librarse de dicha fatalidad e inhumanidad a través de la democratización de los sentimientos. Su suicidio es, también, la muerte de los intentos de democratizar las esferas sociales e individuales. Lo democrático, bajo esta perspectiva, está signado por la resignación desesperada que señala Lukács y que es herencia de la derrota de la burguesía alemana frente al absolutismo. Esta concatenación de degradaciones que el filósofo señala en el párrafo citado son el corolario del prusianismo como ideología. Waldemar, con su resignación desesperada, o el viejo conde Haldern con su cinismo sentimental, son ambos encarnaciones y manifestaciones del prusianismo. El capítulo final de la novela demuestra la frialdad y el cinismo de los Junker, inclusive para con sus propios miembros. En el funeral de Waldemar, una escena llama fuertemente la atención por su sencillez y, al mismo tiempo, por su claridad. Esta tiene relación con la madrastra del joven muerto. El narrador señala que

Eine tiefe Stille trat ein, und die fremden Gäste steckten eben die Köpfe zum Schlußgebet in den Hut, als man hinter einem der Pfeiler ein heftiges und beinah krampfhaftes Schluchzen hörte. Die Gräfin sah empört nach der Stelle hin, von der es kam; aber der deckunggebende Pfeiler ließ glücklicherweise nicht erkennen, wer die Anmaßung gehabt hatte, ergriffener sein zu wollen als sie (Fontane 1973: 265).

La mujer escondida que llora es Stine que, en secreto, observa el funeral de Waldemar. El ofuscamiento de la condesa revela ya su inclinación a mantener la apariencia del duelo, aunque interiormente sienta poca empatía hacia la situación. La apariencia, de este modo, destruye toda emoción real hacia lo humano. La condesa, en su gesto, revela los rasgos barbáricos de los Junker tamizado a través de la posición social y la riqueza material. De manera sutil, Fontane usa el adverbio felizmente para mostrar cómo, ante un eventual descubrimiento de Stine por parte de la condesa, se desplegaría todo el resentimiento ante la expresión honesta y verdadera del dolor. La misma situación aparece unas líneas después de este evento cuando Fontane, como autor, se posiciona en la línea de la normatividad ideológica y expone el deseo de una armonía social a pesar de la muerte. La descripción que realiza el narrador comienza señalando que

In dem letzten Wagen aber saß Waldemars Oheim, den Sommerüberzieher zurückgeschlagen, so daß man das große blaue Ordensland, das des schwedischen Seraphinenordens, in aller Deutlichkeit erkennen konnte. Stine wollte nicht gesehen sein und trat mit halber Wendung zur Seite, der alte Graf aber hatte sie schon von fernher erkannt, und einer flüchtig in ihm aufsteigenden Verlegenheit rasch Herr werdend, erhob er sich im Wagen und lud sie durch eine freundlich-verbindliche Handbewegung zum Einsteigen ein. Über Stines Züge ging ein Leuchten, das der schönste Dank für des alten Grafen, bei Gelegenheiten wie diese, nie versagende Ritterlichkeit war, aber zugleich schüttelte sie den Kopf und ging unter gelegentlichem Verweilen und sich dadurch absichtlich verspätend auf Klein-Haldern zu (Fontane 1973: 266. Las cursivas son del autor).

La respuesta de Stine ante el ofrecimiento del conde concreta la pretensión de Fontane de una armonía social. La galantería del conde, en parte por educación y en parte como expresión de su dominio de clase, oscila entre el cinismo paternalista y el ideal de una bondad mediada por la crueldad, ya que es participe directo de la muerte de Waldemar. Cuando el propio Fontane subraya la palabra nunca, expone la reacción social objetivada de dicha crueldad, en donde confluyen el descaro, la muerte y la imposibilidad de mantener relaciones sociales basadas en el pleno reconocimiento. Así mismo, el brillo de Stine (motivado también por la presencia, no fortuita, de la Orden Seráfica de Suecia) resalta la relación de sumisión entre las clases populares y la aristocracia, en donde las formas sociales enceguecen a los de abajo, de manera que se crea la ilusión de que, en medio de la inhumanidad, existen rasgos aparentemente civilizatorios. De ahí que la novela, en todo su desarrollo, muestre las consecuencias del prusianismo en la vida social, aunque estas traten de ser ocultadas a través de las formas ideales promovidas por los Junker. Finalmente, la novela cierra con la intervención de unos personajes periféricos: Los Polzin. Este matrimonio pequeñoburgués encarna la visión de una sociedad vigilante ante lo que hacen los ciudadanos que buscan quebrantar lo naturalizado. La esposa Polzin escucha la conversación en la barandilla entre la viuda Pittelkow y Stine cuando esta última llega del funeral. Fontane señala que ella «hatte horchend am Treppengeländer oben gestanden und mit nur zu geübtem Ohre jedes der Worte gehört» (Fontane 1973: 268) la conversación. Más allá de 
las claras connotaciones relacionadas al chisme, la oreja entrenada de Polzin revela un síntoma propio de la sociedad burguesa. Por una parte, la necesidad de contrarrestar, mediante la invasión de la vida privada, el profundo tedio que corroe a los sujetos atomizados; por otra parte, evidencia los pilares de lo que luego serán los Estados totales, en donde la escucha atenta de lo que hace el otro es sustancial para mantener el status quo existente. De esta forma, Stine queda anulada como sujeto.«»Nu«, frug er, während er eben das Leder in die Schnalle schob. »Is sie heil wieder da? « »Heil? Was heißt heil? Die wird nich wieder.« »Is eigentlich schade drum.«»I wo. Gar nich... Das kommt davon.«» (Fontane 1973: 268. Las cursivas son del autor). Con este diálogo final de los Polzin Fontane cierra la novela, de forma que la enfermedad y la barbarie son las únicas victoriosas en un mundo petrificado.

\section{Conclusión}

La influencia del prusianismo en la cultura alemana a partir del siglo XIX es, especialmente, relevante para comprender la conformación de una idea de nación y, al mismo tiempo, las consecuencias de una concepción del mundo basada en la represión y la destrucción de toda tentativa por alterar el status quo. El presente artículo buscó revelar dichas articulaciones ideológicas a través de Stine y sus marcas en la formación de la cultura, la sociedad y la literatura del Bismarckzeit. Al analizar la novela, se puede comprender con más profundidad los orígenes sociopolíticos de la deshumanización promovida por los Junker a través del prusianismo, cuyas consecuencias más radicales y terribles se hallan en el nacionalsocialismo. En este sentido, Fontane es un escritor que, a pesar de sus intentos por reconciliar la barbarie con formas civilizadas petrificadas, expone dicha contradicción y el intento, por parte de algunos sujetos, de rebelarse ante la fosilización de la vida. Esta rebelión, sin horizonte y sin esperanza, es el corolario del pesimismo cultural y, al mismo tiempo, el anhelo de una existencia basada en la autonomía y la emancipación de las relaciones sociales. Si bien Fontane busca embellecer, de manera sutil, los estragos causados por las abstracciones objetivadas de la sociedad, muestra los mecanismos de alienación, indefensión y destrucción de los sujetos bajo el incipiente capitalismo alemán. Bajo este orden de producción económica, el espíritu romántico de personajes como Waldemar no solo es visto como algo caduco, sino también apreciado de manera irónica y ridiculizado. De esta manera, conviven diferentes manifestaciones del idealismo. Uno que parte del yo que busca liberarse del mundo social y otro que se sedimenta en lo reaccionario (la hipóstasis de la clase social y de la sangre de, por ejemplo, el viejo conde Haldern). La importancia de Stine como novela se halla en que, de manera concreta, expone dichas transformaciones ideológicas y la asfixia nacida de ellas. Asfixia que será el impulso literario de los movimientos de vanguardia y los pilares negativos del imperialismo alemán. De este modo, la novela de Fontane es la concreción de la pérdida de la identidad de los sujetos bajo la unificación política de Alemania. Unificación ideológica en contraposición a la fragmentación de sus ciudadanos, la vigencia de las reflexiones de Fontane en la novela se hallan, entonces, en la desconexión entre la praxis y la teoría, entre la acción y el pensamiento transformador propias de la atomización capitalista que, hasta la actualidad, se mantiene vigente en el orden democrático-liberal.

Bibliografía:

Bramsted, E. K. (1964). Aristocracy and the middle-classes in Germany: Social types in German literature, 1830-1900. University of Chicago Press.

Fontane, T. (1973). Stine. En Romane und Erzählungen in acht Bänden. Band 5 Aufbau-Verlag.

Hanraths, U. (1989). Das Andere bin ich. Zur Konstruktion weiblicher Subjektivität in Fontanes Romanen. En H. L. Arnold (Ed.), Theodor Fontane (pp. 164-172). Text + Kritik.

Hewitson, M. (2008). Wilhelmine Germany. En J. Ratallack (Ed.), Imperial Germany 18711918 (pp. 40-61). Oxford University Press.

Hübinger, G. (1993). Liberalismus und Individualismus im deutschen Bürgertum.
Neue Folge, 40(1), 60-78.

Jung, W. (2011). Vormärz y Biedermeier, realismo y época de la fundación de imperio. En M. Vedda, (Ed.), El realismo en la Literatura Alemana. Nuevas interpretaciones (pp. 7-34). Editorial de la Facultad de Filosofía y Letras de la Universidad de Buenos Aires.

Krause, E. H. y Hicks, S. V. (1995). Illusion and dissolution: Fontane's Stine. German Studies Review, 18(2), 223-240.

Lepenies, W. (2008). La seducción de la cultura en la historia alemana. Trad.: Jaime Blasco Castiñeyra. Ediciones Akal.

Lerman, K. A. (2008). Bismarckian Germany. En J. Ratallack (Ed.), Imperial Germany 1871-1918 (pp. 18-39). Oxford University
Press.

Lukács, G. (1971). Nueva historia de la literatura alemana. Trad.: Aníbal Leal. Editorial La Pleyade.

Lukács, G. (2019). Sobre el prusianismo. Trad Mariela Ferrari. Inter Litteras, 1, 148 172. https://doi.org/10.34096/interlitteras. n1.7227

Marx, K. (1982). Escritos de juventud. Trad.: Wenceslao Roces. Fondo de Cultura Económica.

Schissler, H. (1980). Die Junker. Zur Sozialgeschichte und historischen Bedeutung der agrarischen Elite in Preußen. Preußen im Rückblick, 6, 89-122. 